\title{
Primary sarcoma of the pancreas, a rare histopathological entity. A case report with review of literature
}

\author{
Peter Ambe ${ }^{1 *}$, Christian Kautz ${ }^{2}$, Shawqi Shadouh ${ }^{3}$, Silvia Heggemann ${ }^{4}$ and Lothar Köhler ${ }^{1}$
}

\begin{abstract}
Aims: primary pancreatic sarcomas represent an extremely rare histopathological entity accounting for less than $0.1 \%$ of all pancreatic malignancies. Pancreatic sarcomas tend to be more aggressive and have a poor prognosis.

Methods: the case of a 52 year old patient presenting with jaundice is presented and the available literature was reviewed.

Results: primary pancreatic sarcomas are extremely rare. Pancreatic sarcomas are more aggressive than other pancreatic neoplasms.

Conclusion: primary sarcomas of the pancreas are extremely rare, are aggressive and are associated with very poor prognosis.
\end{abstract}

\section{Background}

Sarcomas represent a relatively rare malignant entity. Primary sarcomas of the pancreas are even rarer. Amongst pancreatic sarcomas, leiomyosarcomas have been most commonly reported. A review of the literature reveals seven cases of carcinosarcoma. We report a case of epitheloid carcinosarcoma in a young male patient presenting with pancreatitis and jaundice.

\section{Case presentation}

A 52 year old male with a history of chronic alcohol consumption was admitted in the medical department of our community hospital with an acute onset of upper abdominal pain, nausea and vomiting. The diagnostic workup revealed elevated amylase and lipase of 1012U/l and 1160U/l respectively. A swollen edematous pancreas caput and gallbladder stones were evident on upper abdominal ultrasound. At the time of admission, an endoscopic retrograde cholangio-pancreaticography (ERCP) was performed. The common bile duct however could not be visualized. ERCP was repeated after three

\footnotetext{
* Correspondence: peter.ambe@kkh-ne.de

'Department of Surgery, St. Elisabeth Kreiskrankenhaus Grevenbroich,

Akademisches Lehrkrankenhaus der RWTH Aachen, Germany

Full list of author information is available at the end of the article
}

days with papillotomy. A narrow common bile duct without stones or stenosis was visualized [Figure 1].

The patient recovered fully and was discharged after 8 days. One month after discharge the patient was readmitted with right upper quadrant pain and jaundice. The routine workup revealed elevated liver enzymes and bilirubin (total bilirubin: $10.78 \mathrm{mg} / \mathrm{dl}$, direct bilirubin $9.86 \mathrm{mg} / \mathrm{dl}$, indirect bilirubin:0.92 $\mathrm{mg} / \mathrm{dl}$, alkaline phosphatase: $337.64 \mathrm{U} / \mathrm{l})$. Cholecystitis was evident on upper abdominal sonography. Choledocholithiasis was present on ERCP, papillotomy and stone extraction were uneventful. Cholecystectomy was indicated.

Laparoscopic cholecystectomy was performed. During laparoscopy the main bile duct appeared unusally wide even after papillotomy and stone extraction, thus an intraoperative cholangiography was performed. This revealed a significant stenosis in the distal end of the choledochus. The proximal bile duct branches were dilated (Figure 2). An ERCP on day two after cholecystectomy showed a $2 \times 3 \mathrm{~cm}$ measuring ulceration above the papilla of Vateri [Figure 3]. Biopsies revealed an ulcerating malignoma with duodenal infiltration. A stent was placed in the common bile duct. A CT scan of the abdomen revealed a large process of the pancreatic head without signs of mesenteric vessels infiltration [Figure 4].
C Biomed Central

(ㄷ) 2011 Ambe et al; licensee BioMed Central Ltd. This is an Open Access article distributed under the terms of the Creative Commons Attribution License (http://creativecommons.org/licenses/by/2.0), which permits unrestricted use, distribution, and reproduction in any medium, provided the original work is properly cited. 


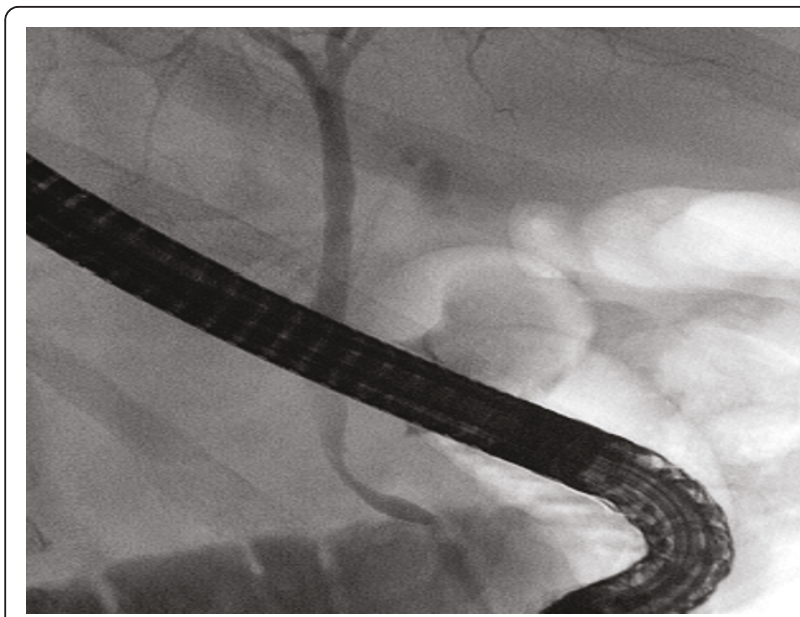

Figure 1 ERCP at the initial presentation. (normal common bile duct on ERCP at the initial presentation).

On laparotomy a large tumor of the pancreatic caput enclosing the superior mesenteric and hepatic arteries with mesenterial infiltration was identified, making a complete resection unlikely. The tumor was left in situ and transduodenal biopsies were taken for histopathology. With a choledochus stent in place, a biliodigestive anastomosis was not indicated. To prevent future bowel obstruction, a gastroenteric anastomosis was constructed using small bowel $40 \mathrm{~cm}$ distal to the ligament of Treitz. The postoperative recovery was uneventful. A venous port system was implanted 10 days after laparotomy. The patient was discharged to our out-patient oncology. Chemotherapy with Gencitabine, 5-Fluorouracil and Folinic acid was initiated.

\section{Histopathology}

Histologic sections revealed large neoplastic cells with epitheloid and sarcomatoid differentiation.

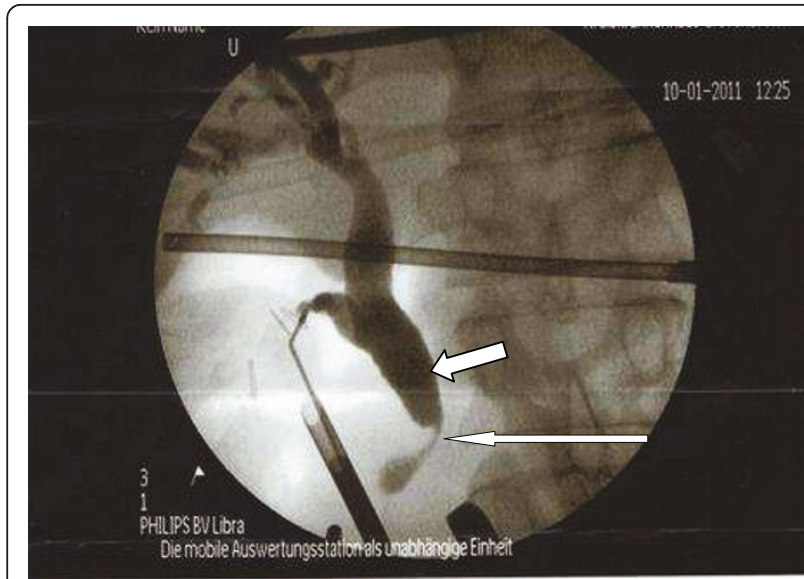

Figure 2 Intraoperative Cholangiogramm. (The thin arrow points at the stenosis, while the thick arrow demonstrates central dilated bile duct system).

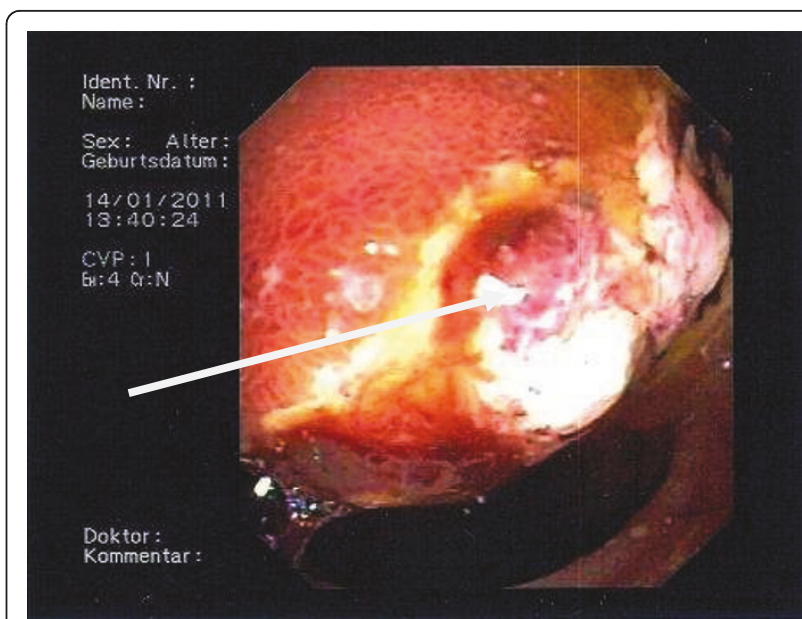

Figure 3 Duodenal ulceration on ERCP. (the arrow points at a 2 $\times 3 \mathrm{~cm}$ ulceration in the duodenum on ERCP).

Immunhistochemical staining demonstrated a coexpression of cytokeratin and vimentin. Stains for Caldesmon, CD 34, CD 31 and S100 were negative. A pure sarcoma or melanoma could be excluded on immunhistochemistry [Figure $5 \mathrm{~A}-\mathrm{C}$ ].

\section{Discussion}

Sarcomas of the pancreas are exceedingly rare. Baylor et al reported a $0.1 \%$ incidence of pancreatic sarcoma after review 5000 cases of pancreatic cancer [1]. Amongst pancreatic sarcomas leiomyosarcomas tend to occur relatively frequent [2]. Epitheloid sarcomas also known as carcinosarcomas represent an even rarer subgroup with very few reported cases in the english literature. Darvishian and colleagues reported the $7^{\text {th }}$ case in the English literature [3]. Thus the incidence of carcinosarcoma as a single entity is expected to be far below $0.1 \%$.

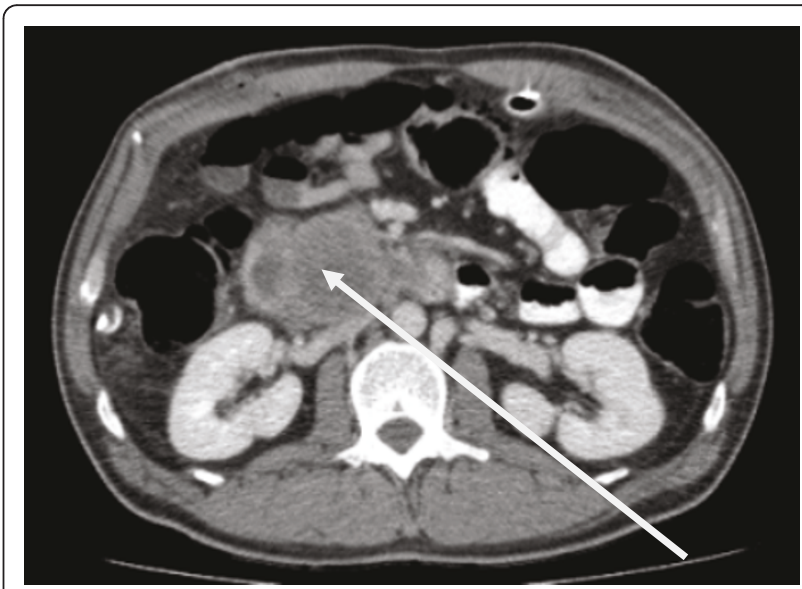

Figure $4 \mathrm{Ct}$ scan of the pancreas. (The arrow marks the enlarged pancreatic caput) 


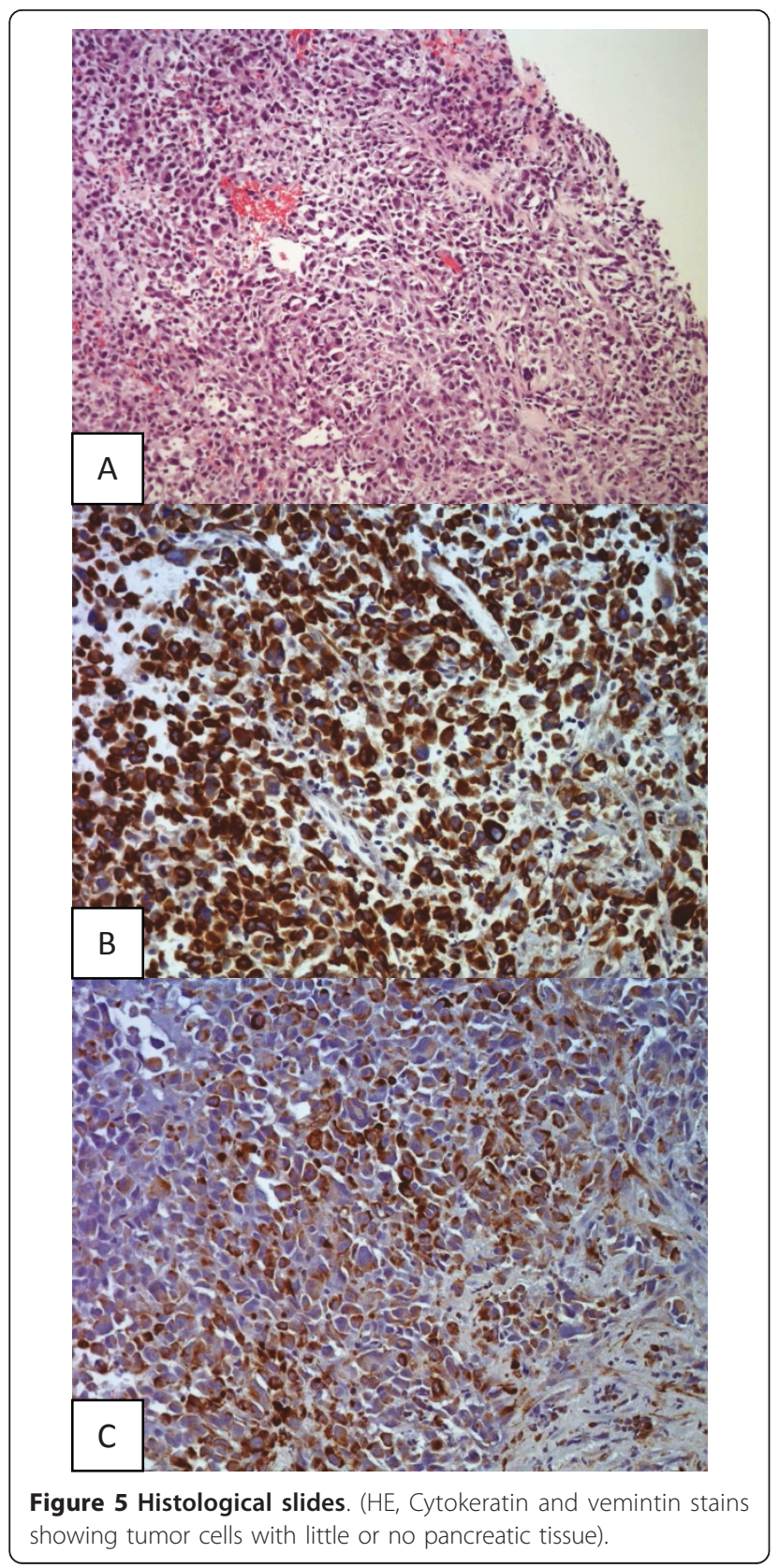

According to Feather et al sarcomas of the pancreas occur frequently in younger individuals. The pancreatic caput is most commonly involved followed by the tail and the body [4]. These features tend to correspond with those in the case presented. The patient, 52 years of age, relatively young, was diagnosed with a sarcoma of the pancreatic caput.

Clinically patients present with colicky pain, nausea and vomiting. These findings are basically similar to those of other pancreatic pathologies and are thus unspecific to sarcomas. Gray and many others consider a painless jaundice as a sign of an advanced lesion [5]. This was true for the case presented.
The diagnosis of pancreatic pathologies is usually confirmed using imaging techniques like ultrasound, computed tomography $(\mathrm{Ct})$, magnetic resonance imaging (MRI), endoscopic retrograde cholangiopancreaticogrphy (ERCP) [6-8].

On initial presentation abdominal ultrasound and ERCP were not suspicious of a pancreatic malignancy as seen in figure 1. A pancreatic process was suspected on an intraoperative cholangiogramm as seen in figure 2 . This was later confirmed on CT and ERCP. To what extend an early ct scan would have confirmed a malignancy remains unclear.

Surgical resection is the only possible cure for pancreatic malignancies. Radical resections are done for localized lesions. Advanced lesions warrant palliation. Potts et al proved the importance of a palliative gastric bypass in advanced stages [9].

In this case, the patient presented with an advanced tumor, so curative resection was not feasible. A palliative gastroenteric anastomosis was done. The common bile duct was not revised since a stent was placed during ERCP [10]. A venous port system was implanted and the patient was sent in for chemotherapy.

Pancreatic cancers generally have a poor prognosis since they tend to be diagnosed in an advanced stage. Sarcomas of the pancreas tend to grow much more rapidly and are believed to be associated with an even worse prognosis [4].

In the case presented, the sarcoma could have grown within three month, i.e between initial presentation in November 2010 and diagnosis in January 2011. This would support the notion that sarcomas tend to grow rapidly. The patient was discharged from the surgical department in a good shape and chemotherapy with Gencitabine, 5- FU and folinic acid was initiated.

\section{Conclusion}

Primary sarcomas of the pancreas are extremely rare. Although little is known about pancreatic sarcomas, they appear to be more aggressive and are associated with a worse prognosis.

\section{Consent}

Written informed consent was obtained from the patient for publication of this case report and accompanying images. A copy of the written consent is available for review by the Editor-in-Chief of this journal

\section{Author details}

'Department of Surgery, St. Elisabeth Kreiskrankenhaus Grevenbroich, Akademisches Lehrkrankenhaus der RWTH Aachen, Germany. 'Department of internal medicine and oncology, St. Elisabeth Kreiskrankenhaus Grevenbroich, Germany. ${ }^{3}$ Institute of Pathology, St. Elisabeth Kreiskrankenhaus Grevenbroich, Germany. ${ }^{4}$ Medical Faculty, RWTH - Aachen, Germany. 


\section{Authors' contributions}

PA, CK and SH did the literature research, PA wrote the article, SS did the pathology, LK edited the article. All the authors reviewed and approved the end version

\section{Conflicts of interests statment}

Drs. Ambe, Kautz, Shadouh, Köhler and cand med. Heggemann have no conflicts of interest or financial ties to disclose.

Received: 5 April 2011 Accepted: 3 August 2011

Published: 3 August 2011

\section{References}

1. Baylor SM, Berg JW: Cross classification and survival characteristics of 5000 cases of cancer of the pancreas. J Surg Oncol 1973, 5:335-358.

2. Zhang H, Jensen MH, Farnell MB, Smyrk TC, Zhang L: Primary Leiomyosarcoma of the Pancreas: Study of 9 Cases and Review of Literature. Am J Surg Pathol 2010, 34:1849-1856.

3. Darvishian F, Sullivan J, Teichberg S, Basham : Carcinosarcoma of the pancreas. Arch Pathol Lab Med 2002, 126:1114-17.

4. Feather $\mathrm{HE}$, Kuhn $\mathrm{CL}$ : Total pancreatectomy for sarcoma of the pancreas. Ann Surg 1951, 134(5):904-912.

5. Howard KGray: Carcinoma of the pancreas. Arch Surg 1948, 57(6):763-773.

6. Karlson BM, Ekbom A, Lindgren PG, Kalskogg V, Rastad J: Abdominal US for diagnosis of pancreatic tumor: prospective cohort analysis. Radiology 1999, 213:107-111.

7. Sheridan MB, Ward J, Guthrie JA, Spencer JA, Craven CM, Wilson D, Guillou PJ, Robinson PJ: Dynamic contrast-enhanced MR imaging and dual-phase helical CT in the preoperative assessment of suspected pancreatic cancer: a comparative study with receiver operating characteristic analysis. AJR Am J Roentgenol 1999, 173:583-590.

8. Adamek HE, Albert J, Breer H, Weitz M, Schilling D, Riemann JF: Pancreatic cancer detection with magnetic resonance cholangiopancreatography and endoscopic retrograde cholangiopancreatography: a prospective controlled study. Lancet 2000, 356:190-193.

9. Potts JR, Broughan TA, Hermann RE: Palliative operations for pancreatic carcinoma. Am J Surg 1990, 159(1):72-78.

10. Goya VRaikar, Matthew MMelin, Ress Andrew, Sara ZLettieri, John JPoterucha, David M, Nagorney und John HDonohue: Cost-effective analysis of surgical palliation versus endoscopic stenting in the management of unresectable pancreatic cancer. Ann Surg Oncol 1995, 3(5):470-475.

doi:10.1186/1477-7819-9-85

Cite this article as: Ambe et al: Primary sarcoma of the pancreas, a rare histopathological entity. A case report with review of literature. World Journal of Surgical Oncology 2011 9:85.

\section{Submit your next manuscript to BioMed Central} and take full advantage of:

- Convenient online submission

- Thorough peer review

- No space constraints or color figure charges

- Immediate publication on acceptance

- Inclusion in PubMed, CAS, Scopus and Google Scholar

- Research which is freely available for redistribution

Submit your manuscript at www.biomedcentral.com/submit
Biomed Central 